\author{
М.А. Павленко, С.М. Балакірева, О.В. Петров
}

Харківський нащіональний університет Повітряних Сил імені Івана Кожедуба, Харків

\title{
РОЗРОБКА КРИТЕРІЮ ВИБОРУ ДОСТОВІРНИХ ЗНАЧЕНЬ УЗАГАЛЬНЕНИХ ХАРАКТЕРИСТИК ПОВІТРЯНИХ ОБ'ЄКТІВ
}

В статті розглянута базова прочедура виведення узагальнених характеристик повітряних об'єктів. Пропонується застосування правил достовірного виведення значень до базової прочедури, щуо дозволяє побудувати нову систему вихідних продукиій. На основі розроблених правил достовірного виведення та перевірки коректності інтегральних узагальнених характеристик повітряних об'єктів запропоновано метод виведення значень узагальнених характеристик повітряних об 'єктів, особливістю якого є поетапна сумісна обробка поточних та апріорних даних і знань про повітряні об'єкти.

Ключові слова: повітряний об'єкт, достовірні значення, правила виведення.

\section{Вступ}

Аналіз сутності та особливостей виконання завдання виведення узагальнених характеристик повітряних об'єктів показує $[1,2]$, що 3 їх допомогою формуються значення узагальнених характеристик повітряних об'єктів. Наявність похибок, неповноти і неоднорідності в поточних даних, що надходять від різних джерел.

На основі базової процедури виведення узагальнених характеристик повітряних об'єктів, моделю процесу отримання названих характеристик на основі знань про нього, виявлено причини труднощів ії реалізації в реальному масштабі часу.

До цих причин були віднесені асинхронність функціонування окремих джерел поточних даних $\mathrm{i}$ складність і багатоетапність обліку невизначеності, неповноти та неоднорідності поточних даних названих джерел.

Одним із шляхів усунення зазначених причин може бути вибір з окремо виведених часткових узагальнених характеристик повітряних об'єктів найбільш достовірних.

Однак для виведення найбільш достовірних значень узагальнених характеристик повітряних об'єктів при наявності узагальнених характеристик повітряних об'єктів, сформованих окремо за даними різних джерел інформації, необхідний вибір. Реалізувати такий вибір можна за допомогою спеціального правила, що дозволяє виводити значення узагаль-

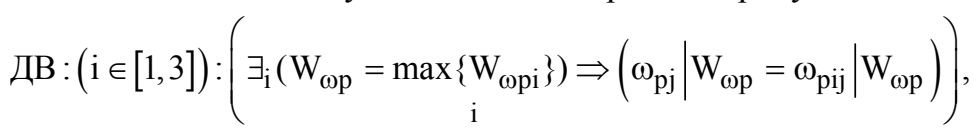

де $\mathrm{p}$ - номер часткової узагальненої характеристики ј-го повітряного об'єкту, при цьому, $\mathrm{p} \in[1,5]$;

$\mathrm{W}_{\omega \mathrm{p}}$ - міра довіри узагальненої характеристики повітряного об'єкту $\omega р$;

$\omega_{\mathrm{pj}}$ - інтегральна узагальнена характеристика j-го повітряного об'єкту. нених характеристик повітряних об'єктів, що володіють найбільшою довірою до них, тобто достовірного виведення узагальнених характеристик повітряних об'єктів.

\section{Основна частина}

Під вірними значеннями узагальнених характеристик повітряного об'єкту будемо розуміти такі значення, які найбільшою мірою відповідають реально існуючим.

Достовірність значень узагальнених характеристик повітряного об'єкту тісно пов'язана з введеними лінгвістичними мірами достовірності поточних даних, що надходять від різних джерел інформації на вхід підсистеми інформаційного забезпечення рішень, а значить, залежить від ступеня їх неоднорідності, неповноти і невизначеності. Тому в якості показника достовірності виведення узагальнених характеристик повітряного об'єкту слід прийняти нечітку міру довіри їх значенням, що отримується шляхом перерахунку лінгвістичних мір достовірності поточних даних при їх обробці спільно зі знаннями про повітряний об'єкт.

Виходячи зі сказаного можна вважати, що достовірними будуть ті значення узагальнених характеристик повітряних об'єктів, виведення яких проводиться за максимальним значенням їх нечітких мір довіри.

Це виведення можна представити у вигляді такого правила-продукції:

Відповідно до наведеного співвідношенням I-АБО граф процедури достовірного виведення узагальненої характеристики повітряного об'єкту в випадках, коли для виведення значень цих характеристик використовуються повідомлення від двох або більше типів різних джерел інформації про по- 
вітряний об'єкт, що володіють різними значеннями лінгвістичних мір достовірності вхідних даних,

може бути представлений графом, наведеними на рис. 1.

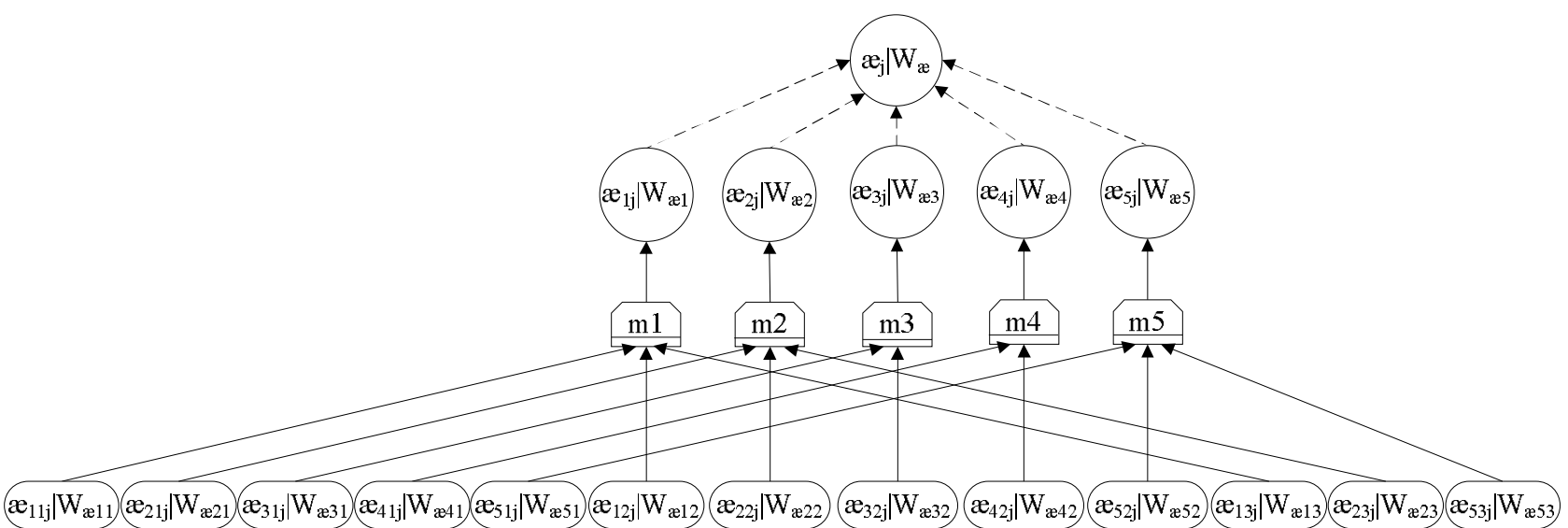

Рис. 1. І-АБО граф процедури достовірності виведення узагальнених характеристик повітряних об'єктів

Правила виведення найбільш вірних значень для кожної узагальненої характеристики ј-го повітряного об'єкту відповідно до їх нечітких мір довіри по суті представляють собою правила достовірного виведення, що можна представити nfrbvb відношеннями:

$$
\begin{aligned}
& \text { ДВ1 : }(\mathrm{i} \in[1,3]):\left(\left(\mathrm{W}_{\omega 11 \mathrm{j}}=\max \left\{\mathrm{W}_{\omega 11}, \mathrm{~W}_{\omega 12}, \mathrm{~W}_{\omega 13}\right\}\right)\right. \\
& \Rightarrow\left(\omega_{1 \mathrm{j}}=\omega_{11 \mathrm{j}}\right), \text { інакше }\left(\mathrm{W}_{\omega 12 \mathrm{j}}=\max \left\{\mathrm{W}_{\omega 11}, \mathrm{~W}_{\omega 12}, \mathrm{~W}_{\omega 13}\right\}\right) \\
& \left.\Rightarrow\left(\omega_{1 \mathrm{j}}=\omega_{12 \mathrm{j}}\right) \text {,інакше }\left(\omega_{1 \mathrm{j}}=\omega_{13 \mathrm{j}}\right)\right) \text {; } \\
& \text { ДВ2 : }(\mathrm{i} \in[1,3]):\left(\left(\mathrm{W}_{\omega 21 \mathrm{j}}=\max \left\{\mathrm{W}_{\omega 21}, \mathrm{~W}_{\omega 22}, \mathrm{~W}_{\omega 23}\right\}\right)\right. \\
& \Rightarrow\left(\omega_{2 \mathrm{j}}=\omega_{21 \mathrm{j}}\right) \text {,інакше }\left(\mathrm{W}_{\omega 22 \mathrm{j}}=\max \left\{\mathrm{W}_{\omega 21}, \mathrm{~W}_{\omega 22}, \mathrm{~W}_{\omega 23}\right\}\right) \\
& \left.\Rightarrow\left(\omega_{2 \mathrm{j}}=\omega_{22 \mathrm{j}}\right) \text {,інакше }\left(\omega_{2 \mathrm{j}}=\omega_{23 \mathrm{j}}\right)\right) \text {; } \\
& \text { ДВ3 }:(\mathrm{i} \in[1,3]):\left(\left(\mathrm{W}_{\omega 31 \mathrm{j}}=\max \left\{\mathrm{W}_{\omega 31}, \mathrm{~W}_{\omega 32}\right\}\right)\right. \\
& \left.\Rightarrow\left(\omega_{3 \mathrm{j}}=\omega_{31 \mathrm{j}}\right) \text {,інакше }\left(\omega_{3 \mathrm{j}}=\omega_{32 \mathrm{j}}\right)\right) \text {; } \\
& \text { ДВ4 }:(\mathrm{i} \in[1,3]):\left(\left(\mathrm{W}_{\omega 41 \mathrm{j}}=\max \left\{\mathrm{W}_{\omega 41}, \mathrm{~W}_{\omega 42}\right\}\right)\right. \\
& \Rightarrow\left(\omega_{4 \mathrm{j}}=\omega_{41 \mathrm{j}}\right) \text {, інакше }\left(\omega_{4 \mathrm{j}}=\omega_{42 \mathrm{j}}\right) \text {; } \\
& \text { ДВ5 : }(\mathrm{i} \in[1,3]):\left(\left(\mathrm{W}_{\omega 51 \mathrm{j}}=\max \left\{\mathrm{W}_{\omega 51}, \mathrm{~W}_{\omega 52}, \mathrm{~W}_{\omega 53}\right\}\right)\right. \\
& \Rightarrow\left(\omega_{5 \mathrm{j}}=\omega_{51 \mathrm{j}}\right) \text {, інакше }\left(\mathrm{W}_{\omega 52 \mathrm{j}}=\max \left\{\mathrm{W}_{\omega 51}, \mathrm{~W}_{\omega 52}, \mathrm{~W}_{\omega 53}\right\}\right) \\
& \left.\Rightarrow\left(\omega_{5 \mathrm{j}}=\omega_{52 \mathrm{j}}\right) \text {,інакше }\left(\omega_{5 \mathrm{j}}=\omega_{53 \mathrm{j}}\right)\right) \text {. }
\end{aligned}
$$

Отримані правила достовірного виведення спільно 3 правилами роздільного виведення значень узагальнених характеристик повітряного об'єкту можуть бути об'єднані в єдину процедуру виведення узагальнених характеристик повітряного об'єкту за даними поточних повідомлень, що надходять від різних джерел, на основі знань про повітряні об'єкти.

Ця процедура, наведена на рис. 2, може бути реалізована в кілька етапів.

Eman 1: Приведення поточних повідомлень різнотипних і асинхронно функціонуючих джерел до єдиної системи координат і часу.
Eman 2: Оцінка наявності та істинності відношень між даними поточних повідомлень і апріорними даними окремо для кожного типу джерел інформації.

Eman 3: Роздільне виведення узагальнених характеристик повітряного об'єкту за фактами оцінки істинності (або хибності) відношень між поточними даними різних джерел інформації i апріорними даними про повітряні об'єкти з визначенням значень нечітких мір довіри цим відношенням 3 відомих лінгвістичним мірам достовірності поточних даних. 


\begin{tabular}{|c|}
\hline $\begin{array}{l}\text { 1. Приведення поточних повідомлень до } \\
\text { єдиної системи координат і часу }\end{array}$ \\
\hline$\nabla$ \\
\hline $\begin{array}{l}\text { 2. Оцінка наявності та істинності } \\
\text { відношень між даними }\end{array}$ \\
\hline$\nabla$ \\
\hline $\begin{array}{c}\text { 3. Роздільне виведення узагальнених } \\
\text { характеристик повітряних об'єктів за } \\
\text { фактами оцінки істинності (або хибності) }\end{array}$ \\
\hline$\nabla$ \\
\hline $\begin{array}{l}\text { 4. Відбір найбільш вірних значень } \\
\text { узагальнених характеристик } \\
\text { повітряних об'єктів }\end{array}$ \\
\hline$\nabla$ \\
\hline $\begin{array}{c}\text { 5. Формування інтегральних } \\
\text { узагальнсних характеристик } \\
\text { повітряних об'єктів }\end{array}$ \\
\hline
\end{tabular}

Рис. 2. Процедура виведення узагальнених характеристик повітряного об'єкту

Eman 4: Відбір найбільш вірних значень узагальнених характеристик повітряного об'єкту за максимальним значенням нечітких мір довіри цим характеристикам, отриманим шляхом перерахунку нечітких мір довіри відношенням, розрахованим на попередньому етапі.

Eman 5: Формування інтегральних узагальнених характеристик повітряного об'єкту з найбільш достовірних значень їх часткових узагальнених характеристик.

Достовірний вивід значень здійсненюється для кожної часткової узагальненої характеристики повітряного об'єкту за максимальним значенням нечітких мір довіри окремо виведених узагальнених характеристик повітряного об'єкту. При цьому повинні використовуватися ДВ1, ..., ДВ5.

Результатом такого виводу повинна бути сукупність часткових узагальнених характеристик, яка може бути представлена у вигляді такої множини:

$$
\begin{gathered}
\omega_{\mathrm{j}}\left|\mathrm{W}_{\omega}=\omega_{\mathrm{j}}\right|\left\{\mathrm{W}_{\omega \mathrm{i}}\right\}= \\
=\left\{\omega_{1 \mathrm{j}}\left|\mathrm{W}_{\omega 1}, \omega_{2 \mathrm{j}}\right| \mathrm{W}_{\omega 2}, \omega_{3 \mathrm{j}}\left|\mathrm{W}_{\omega 3}, \omega_{4 \mathrm{j}}\right| \mathrm{W}_{\omega 4}, \omega_{5 \mathrm{j}} \mid \mathrm{W}_{\omega 5}\right\},
\end{gathered}
$$

в якому значення складових визначаються відповідно до вираження продукції ДВ.

Подання інтегральних узагальнених характеристик повітряних об'єктів, отриманих в результаті застосування наведеної системи продукцій, можуть відрізнятися від їх реальних представлень в зв'язку з наявністю в поточних даних, що надходять від джерел інформації, неоднорідності, неточностей і неповноти.
Тому виникає необхідність в доповненні описаної процедури достовірного виведення операцією перевірки коректності інтегральних узагальнених характеристик повітряних об'єктів їх реальним характеристикам.

Відомо [3, 4], що причинами некоректності виведених знань, крім того, можуть бути помилки формалізації вихідних даних і знань, недостатнє врахування їх особливостей і особливостей застосовуваних формальних систем, а також недостатне врахування початкових умов для реалізації виведення. Усунути ці причини повністю не завжди представляється можливим.

Однак виявити їх і в достатній мірі компенсувати можна різними методами на різних етапах експлуатації систем штучного інтелекту.

До цих методів віднесемо:

на етапі придбання та поповнення знань - вибір відповідного апарату формалізації;

на етапі формування бази знань - метод іiї тестування, тобто складання набору вихідних даних i початкових умов, що забезпечують заздалегідь відомий результат;

на етапі побудови програмних засобів - вивід знань шляхом використання спеціальних методик, що базуються на особливостях використовуваних моделей і методів представлення знань і формальних систем;

на етапі практичного застосування систем штучного інтелекту, коли склад їх баз знань визначено, побудова еталонів відношень (тимчасових, просторових, каузальних) між виведеними і об'єктивно існуючими знаннями.

Вивчення умов практичного використання підсистеми інформаційного забезпечення рішень показує:

по-перше, в ній база знань повинна бути визначена заздалегідь,

по-друге, виведення знань про характеристики повітряних об'єктів проводиться в рамках вузького аспекту і одного рівня знань,

по-трете, знання про характеристики повітряних об'єктів накопичуються і формуються в процесі експлуатації підсистеми інформаційного забезпечення рішень.

Все це дозволяє зробити висновок про те, що для оцінки коректності формованих описів інтегральних узагальнених характеристик повітряних об'єктів можна використовувати еталонні описи цих характеристик, або еталони комбінацій часткових узагальнених характеристик. Для перевірки коректності виведених знань про повітряні об'єкти були використані зразки тимчасових просторових і каузальних відношень.

У разі оцінки коректності інтегральних узагальнених характеристик повітряних об'єктів необ- 
хідно ввести в розгляд еталони структурних (поелементних) відношень між виведеними інтегральними узагальненими характеристиками повітряних об'єктів і можливими варіантами об'єктивно (реально) існуючих комбінацій часткових узагальнених характеристик.

3 огляду на ту обставину, що інтегральна узагальнена характеристика повітряних об'єктів є сукупністю часткових узагальнених характеристик цих об'єктів, то для побудови правила оцінки коректності інтегральних узагальнених характеристик необхідно скласти перелік варіантів реально можливих комбінацій часткових узагальнених характеристик повітряних об'єктів на основі вивчення технічних можливостей повітряних об'єктів.

3 урахуванням вище викладеного правило оцінки коректності інтегральної узагальненої характеристики ј-го повітряного об'єкту може бути сформульоване таким чином: якщо виведена сукупність значень часткових узагальнених характеристик ј-го об'єкту $æ_{\text {рj }}$ співпадає поелементно хоч би з одним 3 еталонів інтегральних узагальнених характеристик $\omega_{\mathrm{pm}}^{\mathrm{k}}$, то сформована інтегральна характеристика $\mathrm{j}$ го об'єкту $æ_{j} \epsilon$ коректною, або реально можливою, другу позначимо як $\omega_{\mathrm{j}}^{\mathrm{R}}$.

У аналітичному вигляді це правило можна записати таким чином:

$$
\begin{aligned}
& \mathrm{KB}:(\mathrm{m} \in[1,60]):\left(\exists_{\mathrm{m}}\left(\omega_{\mathrm{pj}}=\omega_{\mathrm{pm}}^{\mathrm{k}}\right) \Rightarrow\left(\omega_{\mathrm{j}}=\omega_{\mathrm{j}}^{\mathrm{R}}\right),\right. \\
& \quad(\rho \in[1,5], \mathrm{j} \in[1, \mathrm{~S}])
\end{aligned}
$$

Отримане правило дозволяє зробити остаточний висновок про зміст і реальність інтегральних узагальнених характеристик повітряних об'єктів, які сформовані підсистемою інформаційного забезпечення рішень.

\section{Висновки}

Запропоновано застосування правил достовірного виведення значень до базової процедури, що дозволяє побудувати нову систему вихідних продукцій. На основі розроблених правил запропоновано метод виведення значень узагальнених характеристик повітряних об'єктів. Рішення завдання виведення узагальнених характеристик повітряних об'єктів за максимальним значенням мір довіри цим узагальнених характеристик повітряних об'єктів передбачає розробку спеціальних правил достовірного виведення, в результаті якого менш достовірні значення узагальнених характеристик повітряних об'єктів відкидаються. Це дозволяє підвищити достовірність результатів виведення.

\section{Список літератури}

1. Зайцев Д.В., Наконечний А.П., Пахарєв С.О., Луиенко I.О.; за ред. В. Б. Добровольського. Військова розвідка: навчальний посібник / упорядники :- К. : Видавничополіграфічний центр "Київський університет", 2016. 335 c. [Електронний ресурс]. Режим доступа: http://www.mil.univ.kiev.ua/files/224_1596505657.pdf

2. Глєбов Ю.В., Королюк Н.О., Павленко М.А., Тимочко О.І., Оніпченко П.М., Петров О.В., Двухглавов Д.Е., Корольов Р.В. Об'єкти управління автоматизованих систем управління Повітряних Сил: навчальний посібник. Х.: ХУПС, 2015. - $256 c$

3. Ярушек В.Е., Прохоров В.П., Судаков Б.Н., Мишин A.В. Теоретические основы автоматизачии прочессов выработки решений в системах управления. - Харьков: $X B У, 1993 .-446 c$.

4. Бондарев В.Н., Аде Ф.Г. Искусственныий интеллект: Учебное пособие для вузов. - Севастополь: СевНТУ, 2002. $-615 c$.

Надійшла до редколегії 18.12.2017

Рецензент: д-р техн. наук, проф. О.І. Тимочко, Харківський національний університет Повітряних Сил імені Івана Кожедуба, Харків.

\title{
РАЗРАБОТКА КРИТЕРИЯ ВЫБОРА ДОСТОВЕРНЫХ ЗНАЧЕНИЙ ОБОБЩЕННЫХ ХАРАКТЕРИСТИК ВОЗДУШНЫХ ОБЪЕКТОВ
}

\author{
М.А. Павленко, С.М. Балакірева, А.В. Петров
}

В статье рассмотрена базовая проиедура вывода обобщенных характеристик воздушных объектов. Предлагается применение правил достоверного вывода значений к базовой прочедуре, что позволяет построить новую систему выходных продукций. На основе разработанных правил достоверного вывода и проверки корректности интегральных обобщенных характеристик воздушных объектов предложен метод вывода значений обобщенных характеристик воздушных объектов противника, особенностью которого является поэтапная совместная обработка текущих и априорных данных и знаний о воздушном объекте.

Ключевые слова: воздушный об'єкт, достоверные значения, правила вывода.

\section{DEVELOPMENT OF CRITERION OF CHOICE OFRELIABLE VALUES GENERALIZED DESCRIPTIONS OF AIR OBJECTS}

\section{M.A. Pavlenko, S.M. Balakireva, A.V. Petrov}

Base procedure of leadingout of the generalized descriptionsof air objects is considered in the article. Application of rules of reliable leadingout of values is offeredto base procedure, that allows to build the new system ofweekend of npoдукиий. On the basis of the worked out rulesof reliable leadingout and verification of correctness of theintegral generalized descriptions of air objects the method ofleadingout of values of the generalized descriptions of airobjects of opponent the feature of that is the stageby-stagecompatible processing of and a priori current data andknowledge about air objects.

Keywords: air object, reliable values, rules of leadingout. 